\title{
ANALISIS ETIKA BISNIS DAN KUALITAS PELAYANAN TERHADAP KEPUASAN PELANGGAN DI PT. MODERN MULTI KEMASINDO - TANGERANG
}

\author{
Tri Endi Ardiansyah ${ }^{1}$ \\ Fakultas Ekonomi dan Bisnis, Universitas Muhammadiyah Tangerang \\ triendisasongko@gmail.com \\ Iwan Rofiq Setiawan ${ }^{2}$ \\ Fakultas Ekonomi dan Bisnis, Universitas Muhammadiyah Tangerang \\ iwanrs@gmail.com \\ Elin Rahmantika ${ }^{3}$ \\ Fakultas Ekonomi Dan Bisnis, Universitas Muhammadiyah Tangerang
}

\begin{abstract}
ABSTRAK
Banyak Kasus bisnis yang terjadi, dimana di masa awal usahanya sangat baik namun harus kandas dalam waktu yang relatif singkat hanya karena tingginya kekecewaan pelanggan sebagai dampak dari etika bisnis yang tidak diterapkan dengan baik. Tujuan dari penelitian ini adalah untuk mengetahui pengaruh etika bisnis dan kualitas pelayanan terhadap kepuasan pelanggan di PT. Modern Muti Kemasindo secara simultan maupun parsial. Penelitian ini menggunakan pendekatan kuantitatif. Sampel pada penelitian ini adalah 92 responden dari total populasi120 pelanggan aktif PT. Modern Multi Kemasindo. Data yang digunakan adalah data primer dengan survey dan kuisioner. Hasil penelitian menunjukkan bahwa secara parsial etika bisnis (X1) berpengaruh positif dan signifikan terhadap kepuasan pelanggan dan kualitas Pelayanan (X2) secara parsial berpengaruh positif dan signifikan terhadap kepuasan Pelanggan. Secara simultan etika bisnis $\left(\mathrm{X}_{1}\right)$ dan kualitas Pelayanan $\left(\mathrm{X}_{2}\right)$ berpengaruh positif dan signifikan terhadap kepuasan Pelanggan $(\mathrm{Y})$. Besarnya pengaruh yang diberikan oleh variabel etika bisnis $\left(\mathrm{X}_{1}\right)$ dan variabel kualitas pelayanan $\left(\mathrm{X}_{2}\right)$ terhadap kepuasan pelanggan adalah $54,4 \%$ sedangkan sisanya $45,6 \%$ adalah dipengaruhi oleh faktor lain yang tidak diteliti dalam penelitian ini.
\end{abstract}

\section{Kata Kunci : Etika Bisnis, Kualitas Pelayanan, dan Kepuasan Pelanggan}

\begin{abstract}
Many business cases have occurred, where in the early days of their business were very good but it had to run aground in a short time because of high customer disappointment as a result of poor business ethics implementation. The purpose of this research was to determine the effect of business ethics and service quality on customer satisfaction at PT. Modern Muti Kemasindo as simultaneously or partially. This research uses a quantitative approach. The samples in this research were 92 respondents from total population of 120 active customers of PT. Modern Multi Kemasindo. The data used are primary data with surveys and questionnaires. The results showed that partially business ethics $\left(X_{1}\right)$ had a positive and significant effect on customer satisfaction and service quality $\left(X_{2}\right)$ partially had a positive and significant effect on customer satisfaction. Simultaneously, business ethics $\left(X_{1}\right)$ and service quality $\left(X_{2}\right)$ have a positive and significant effect on customer satisfaction $(Y)$. The amount of influence given by the business
\end{abstract}


ethics variable $\left(X_{1}\right)$ and the service quality variable $\left(X_{2}\right)$ on customer satisfaction is $54.4 \%$ while the remaining $45.6 \%$ is influenced by other factors not examined in this research.

Key words: Business Ethics, Service Quality, Customer Satisfaction

\section{A. PENDAHULUAN}

Sebagai suatu institusi bisnis, perusahaan tidak saja memiliki tanggung jawab ekonomi dan hukum saja namun juga memiliki tanggung jawab sosial secara etis kepada pemegang saham maupun pada stakeholder yang berkaitan dengan aktivitas bisnisnya. Praktik-praktik non etis yang dilakukan oleh pelaku usaha memiliki pengaruh terhadap kinerja usaha dan nilai/value usaha. Seiring dengan berkembangnya industri, hal ini mendorong bertumbuh pesatnya industri kemasan. Tentunya hal ini juga menciptakan tingginya intensitas persaingan serta menuntut perusahaan untuk selalu memperhatikan kebutuhan dan keinginan konsumen.

Pada Maret 2019 tercatat sebanyak 330 unit usaha kemasan dari kertas dan karton yang terdaftar di wilayah Tangerang (Kemenperin, 2019). Tentunya hal ini menciptakan persaingan industri dalam mempertahankan pasar dan pelanggan. Hal ini mendorong pelaku usaha di dalamnya untuk berlomba dalam meningkatkan kepuasan pelanggan. Salah satu faktor yang mempengaruhi kepuasan pelanggan adalah kualitas pelayanan. Kualitas pelayanan yang baik akan menghasilkan dorongan kepada pelanggan untuk menjalin hubungan yang kuat dengan perusahaan, dalam jangka panjang.

PT. Modern Multi Kemasindo sebagai perusahaan yang bergerak di industri kemasan karton telah memiliki mesin yang mampu mencetak kemasan karton untuk produk elektronik dan melayani wilayah Tangerang dan sekitarnya. Permasalahan yang kadang terjadi pada proses pemesanan sampai dengan pengiriman produk diantaranya kendala kerusakan mesin, keterbatasan armada pengiriman, dan kendala administrative lainnya. Di lain hal, banyaknya permasalahan yang bersifat nonteknis mengakibatkan keluhan dari pelanggan seperti: kualitas produk yang kurang baik, cetakan atau ukuran kemasan karton yang tidak sesuai pesanan, keterlambatan pengiriman, penagihan dan pembayaran, dan sebagainya. Permasalahan atau komplain tersebut biasanya langsung disampaikan kepada departemen. Beberapa hal yang berisat ketidak sesuaianmutu dan kesalahan komunikasi kerap dianggap oleh konsumen sebagai pengingkaran kesepakatan pemesanan dan pengerjaan dan kelalaian bisnis dimana hal tersebut berujung pada pencitraan perusahaan.

Penelitian ini bertujuan untuk mengetahui pengaruh etika bisnis dan kualitas pelayanan terhadap kepuasan pelanggan di PT. Modern Muti Kemasindo secara maupun parsial simultan.

\section{B. KAJIAN LITERATUR DAN PENGEMBANGAN HIPOTESIS}

\section{Pemasaran}

Pemasaran (marketing) adalah suatu sistem total dari kegiatan bisnis yang dirancang untuk merencanakan, 
menentukan harga, mempromosikan dan mendistribusikan barang-barang yang dapat memuaskan keinginan dan jasa baik kepada para konsumen saat ini maupun konsumen potensial (Thamrin dan Francis, 2018). Pada implementasinya Pemasaran adalah suatu penggabungan atau kombinasi variabel atau kegiatan yang merupakan inti dari sistem pemasaran, variabel mana dapat di kendalikan oleh pemasaran untuk mempengaruhi reaksi para pembeli atau konsumen sehingga menjadi suatu bauran yang disebut dengan bauran Pemasaran atau marketing mix (Assauri, 2013). Marketing mix terdiri atas empat Komponen atau disebut $4 \mathrm{P}$ yaitu product, price, place, promotion.

Dalam kajian strategi bisnis dikenal kaidah STP (Segmenting, Targeting, and Positioning), dimana STP sering dipadukan dengan marketing mix sehingga menjadi substansi dasar dalam strategi pemasaran produk ataupun jasa (Kotler, 2012). Segmenting (Segmentasi Pasar) adalah sebagai proses mengelompokkan pasar keseluruhan yang heterogen menjadi kelompok-kelompok yang memiliki kesamaan dalam hal kebutuhan, keinginan, perilaku, dan atau respon terhadap program pemasaran spesifik. Targeting/Market Targeting (Sasaran Pasar) diartikan sebagai proses mengevaluasi daya tarik segmen pasar dan memilih satu atau beberapa untuk dimasuki. Positioning adalah cara produk, merek, atau organisasi perusahaan dipersepsikan secara relatif dibandingkan dengan produk, merek atau organisasi pesaing oleh pelanggan.

\section{Etika Bisnis}

Etika bisnis dalam suatu
perusahaan dapat membentuk nilai,
norma, dan perilaku karyawan serta
pimpinan dalam membangun hubungan
yang adil dan sehat dengan pelanggan
atau mitra kerja (Prihanto, 2018). Ilmu
etika bisnis telah melahirkan berbagai
teori, dimana setiap teori memiliki
pandangan masing-masing dalam
menempatkan permasalahan etika bisnis. Adapun Teori yang menjadi pendekatan dalam penerapan etika bisnis adalah : Teori Deontology, Teori Teleogy, Teori hak asasi, Teori keutamaan, Teori Relatif, dan Teori pendekatan agama (Fahmi, 2017). Tujuan pemberlakuan etika bisnis yaitu: pertama untuk mendapatkan konsep yang sama mengenai penilaian baik dan buruknya perilaku atau tindakan manusia. Kedua, mengarahkan perkembangan masyarakat menuju suasana yang harmonis, tertib, teratur, damai dan sejahtera. Ketiga, mengajak orang bersikap kritis dan rasional dalam mengambil keputusan secara otonom (Badroen, 2015).

Etika bisnis memiliki prinsip-prinsip umum yang dijadikan acuan dalam melaksanakan kegiatan dan mencapai tujuan. Adapun prinsip-prinsip etika bisnis tersebut adalah sebagai berikut:

a. Otonomi, adalah sikap dan kemampuan manusia untuk mengambil keputusan dan bertindak berdasarkan kesadarannya tentang apa 
yang dianggapnya baik untuk dilakukan. Adapun indikatornya adalah : pertama memberikan produk dengan kualitas yang sesuai dengan tuntutan pelanggan, kedua perlakuan yang humanis kepada pelanggan termasuk pelayanan yang prima dan menindaklanjuti keluhan pelanggan, ketiga jaminan atas kesehatan dan keselamatan pelanggan juga kualitas lingkungan selama interaksi bisnis berlanjut.

b. Kejujuran, adapun indikatornya adalah: pertama kejujuran dalam pemenuhan syarat-syarat perjanjian dan kontrak, kedua kejujuran dalam penawaran produk dengan sebanding mutu dan harga yang ditawarkan, ketiga Kejujuran dalam hubungan kerja intern dalam suatu perusahaan yaitu antara pemberi kerja dengan pekerja, dan berkaitan dengan kepercayaan.

c. Prinsip keadilan, adapun yang menjadi indikatornya adalah: pertama Keadilan legal dimana keadilan ini menuntut agar negara bersikap netral dalam memperlakukan semua pelaku ekonomi dan semua pelaku bisnis harus tunduk dengan aturan dan hukum bisnis yang berlaku, kedua Keadilan komunitatif dimana hal ini berlaku sebagai kejadian tukar, yaitu menyangkut pertukaran yang fair antara pihak-pihak yang terlibat, ketiga Keadilan distributif atau disebut juga keadilan ekonomi, yaitu berkaitan dengan prinsip perlakuan yang sama sesuai dengan aturan dan ketentuan dalam perusahaan yang juga adil dan baik.

d. Hormat pada Diri Sendiri, Sikap hormat pada diri sendiri dapat diwujudkan dengan menjaga kesucian fisik dan menjaga kesucian rohani. Adapun yang menjadi indikator di dalamnya adalah: pertama Menjaga kesehatan karyawannya, kedua memenuhi hak-hak karyawan dalam hal kesesuaian jam kerja, ketiga Menyediakan waktu dan tempat ibadah.

\section{Kualitas Pelayanan}

Kualitas pelayanan diwujudkan melalui pemenuhan kebutuhan dan keinginan pelanggan serta ketepatan penyampaiannya dalam mengimbangi atau melampaui harapan pelanggan (Sangadji dan Sopiah, 2013). Pada dasarnya kualitas pelayanan atau jasa dari sudut penilaian pelanggan dibedakan atas tiga dimensi (Farida, 2017). Adapun ketiga dimensi menadi indikator kualitas Pelayanan adalah sebagai berikut :

a. Technical atau outcome, konsumen menghendaki agar penyedia layanan apakah kontak personel, sistem operasi, maupu peralatan-peralatan teknik yang dimiliki haruslah dapat mengatasi masalah yang dihadapinya secara profesional dan terampil.

b. Functional atau process related, yaitu berkaitan dengan cara jasa disampaikan atau disajikan. Adapun Indikatornya antara lain: pertama Attitudes and behavior dimana konsumen harus merasa yakin bahwa personel melayani dan berusaha 
membatu dalam memecahkan masalah mereka secara spontan dan dengan cara bersahabat, kedua Accessbility and flexibility dimana konsumen merasa dapat melakukan akses dengan mudah, permintaan dapat disesuaikan dengan keinginan konsumen dengan cara yang lebih fleksibel, ketiga Reliability and trustworthiness dimana konsumen bisa mempercayakan segala sesuatunya kepada penyedia jasa, baik kepada karyawan maupun sistemnya untuk memegang janjinya, keempat Recovery dimana konsumen merasa yakin penyedia jasa akan dapat megatasi permasalahan yang terjadi dengan tepat, sesuai dengan harapan mereka.

c. Corporate image, yaitu berkaitan dengan citra perusahaan di mata konsumen (Reputation and credibility) dimana pelanggan percaya bahwa operasi atau cara kerja penyedia jasa dapat dipercaya dan memberikan nilai atau imbalan yang sesuai dengan pengorbanannya.

\section{Kepuasan Pelanggan}

Kepuasan adalah hasil dari penilaian konsumen bahwa produk atau jasa pelayanan telah memberikan tingkat kenikmatan dimana tingkat pemenuhan ini bisa lebih atau kurang (Sudaryono, 2014). Kepuasan pelanggan adalah hasil yang dirasakan pembeli dari kinerja perusahaan yang memenuhi harapan mereka. Kepuasan pelanggan akan timbul apabila kebutuhan dan keinginan pelanggan terpenuhi oleh produk atau jasa yang berkualitas (Thamrin dan Francis, 2018).

Menurut Hawkins dan Lonney pengukuran tingkat kepuasan pelanggan pada umumnya dengan membentuk beberapa atribut yang telah dibakukan sebagai bagian dari proses Pemasaran yang berlangsung selama ini. Adapun indikator-indikator kepuasan pelanggan dirumuskan sebagai berikut:

a. Kesesuaian harapan, dengan atribut indikatornya adalah: pertama kesesuaian produk, kedua kekesuaian Pelayanan, ketiga kesesuaian fasilitas penunjang.

b. Minat menggunakan kembali, dengan atribut indikatornya adalah: pertama minat beli kembali karena kualitas produk yang baik, kedua minat membei kembai karena pelayanan yang prima, ketiga minat beli kembali karena merasakan nilai dan manfaat Setelah membeli.

c. Kesediaan merekomendasikan, dengan atribut indikatornya : pertama merekomendasikan oran lain untuk membeli produk kualitas produk yang baik, kedua merekomendasikan orang lain untuk membeli karena ketersediaan fasilitas penunjang yang memadai, ketiga merekomendasikan orang lain untuk membeli karena karena nilai atau manfaat yang didapat setelah mengkonsumsi produk tersebut (Tjiptono, 2012).

\section{Kerangka Konseptual}

Kerangka konseptual merupakan suatu bentuk kerangka berpikir yang 
dapat digunakan sebagai pendekatan dalam memecahkan masalah. Umumnya hal ini menggunakan pendekatan ilmiah dan memperlihatkan hubungan antar variabel dalam proses analisisnya (Sugiyono, 2018). Untuk merumuskan hipotesis dalam penelitian ini, maka dapat dibuat kerangka konseptual sebagai berikut :

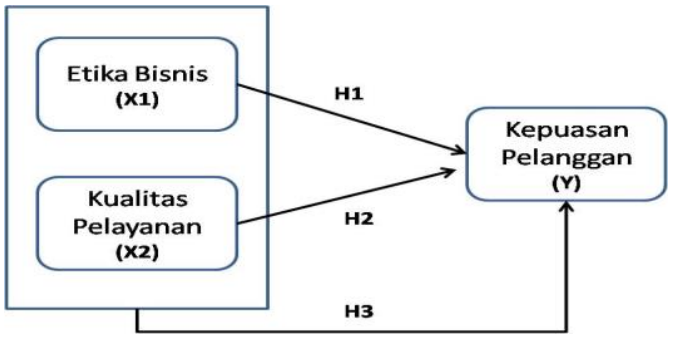

Gambar 1

Kerangka Konseptual

\section{Perumusan Hipotesis}

Hipotesis merupakan jawaban sementara terhadap masalah penelitian, dimana rumusan masalah penelitian telah dinyatakan dalam bentuk kalimat pernyataan (Sugiyono, 2018).

a. Pengaruh Etika Bisnis Terhadap

Kepuasan Pelanggan, etika bisnis memberikan suatu dorongan kepada pelanggan untuk menjalin ikatan hubungan yang kuat dengan perusahaan

$\mathrm{H} 1$ : Diduga Etika Bisnis $\left(\mathrm{X}_{1}\right)$ berpengaruh terhadap Kepuasan Pelanggan (Y)

b. Pengaruh Kualitas Pelayanan Terhadap Kepuasan Pelanggan. kualitas pelayanan perlu ditingkatkan dan dijaga agar pelanggan merasa terpuaskan.

$\mathrm{H}_{2}$ : Diduga Kualitas Pelayanan $\left(\mathrm{X}_{2}\right)$ berpengaruh terhadap Kepuasan Pelanggan (Y) c. Pengaruh Etika Bisnis Dan Kualitas Pelayanan terhadap Kepuasan Pelanggan.

Penerapan etika bisnis dan kualitas pelayanan harus lebih ditingkatkan lagi agar pelanggan merasa puas menciptakan sikap loyal dari pelanggannya.

$\mathrm{H}_{3}$ : Diduga Etika Bisnis $\left(\mathrm{X}_{1}\right)$ dan Kualitas Pelayanan $\left(\mathrm{X}_{2}\right)$ berpengaruh terhadap Kepuasan Pelanggan (Y)

\section{METODE PENELITIAN}

\section{Pendekata Penelitian}

Penelitian dengan pendekatan Kuantitatif, dimana metode pendekatan ini berlandaskan pada filsafat positivisme, digunakan untuk meneliti pada populasi atau sampel tertentu, pengumpulan data menggunakan instrumen penelitian, analisis data bersifat kuantitatif. Jenis data yang digunakan dalam penelitian ini adalah Cross selectional, yaitu kegiatan riset yang dilakukan pada suatu saat tertentu.

\section{Definisi dan Pengukuran Variabel}

Dalam penelitian terdiri dari dua variabel, yaitu variabel independen dan variabel dependen. Adapun penjelasan dari masing-masing variabel itu dalah sebagai berikut:

a. Variabel Independen atau Variabel Bebas.

Pada penelitian yang dilakukan peneliti variabel independen adalah Etika Bisnis $\left(\mathrm{X}_{1}\right)$ dan Kualitas Pelayanan $\left(\mathrm{X}_{2}\right)$. 
b. Variabel Dependen atau Variabel Terikat

Pada penelitian yang dilakukan peneliti variabel dependen adalah Kepuasan Pelanggan (Y).

\section{Operasional Variabel}

Skala pengukuran menggunakan skala Likert untuk mengukur sikap, pendapat, dan persepsi seseorang atau sekelompok orang tentang fenomena sosial. Operasional variabel dengan menginterprestasikan variabel-variabel yang dapat menyebabkan masalah lain dari variabel lain dengan mengurai dimensi di dalamnya:

a. Etika Bisnis $\left(\mathrm{X}_{1}\right)$, dimensinya adalah : Otonomi, Kejujuran, Keadilan, Hormat pada diri sendiri.

b. Kualitas Pelayanan $\left(\mathrm{X}_{1}\right)$, dimensinya adalah : Technical atau outcome, Functional atau process related., Corporate image

c. Kepuasan Pelanggan (Y), dimensinya adalah : Kesesuaian harapan., Minat menggunakan kembali., Ketersediaan merekomendasikan.

\section{Populasi Dan Sampel}

Pada penelitian ini populasinya adalah jumlah pelanggan yang masih aktif bertransaksidi PT. Modern Multi Kemasindo pada tahun 2019 adalah berjumlah 120 pelanggan. Pengambilan sampel menggunakan metode rumus Slovin dengan batas toleransi kesalahan $5 \%$ maka diidapatkan responden sebanyak 92 orang.

\section{Metode Dan Teknik Pengumulan Data}

Pengumpulan data pada penelitian ini dengan menggunakan data primer dan data sekunder. Data primer, yaitu : interview/wawancara, kuisioner dan observasi lapangan. Dalam kuesioner ini terdapat alternative jawaban yang disusun dalam 5 (lima) alternatif and responden dapat memilih salah satu jawaban yang dianggap benar. Semakin tinggi skor jawaban berarti responden makin setuju dengan pernyataan atau pertanyaan yang disajikan. Data sekunder yaitu : studi perpustakaan (Library research), jurnal, dan internet.

\section{Metode Analisis Data}

Analisis data yang digunakan pada penelitian ini adalah analisa statistik deskriptif. Teknik yang digunakan dalam pengujian instrument meliputi uji validitas dan uji reliabilitas.

a. Uji Validitas, bertujuan untuk menguji sejauh mana item kuesioner yang valid dan mana yang tidak valid.

b. Uji Reliabilitas, adalah instrumen yang bila digunakan beberapa kali untuk mengukur obyek yang sama, akan menghasilkan data yang sama. Suatu konstruk atau variabel dikatakan reliabel jika memberikan nilai Cronbach Alfa> 0,60.

Sedangkan uji asumsi klasik pada penelitian ini menggunakan uji normalitas, uji multikolinieritas, uji heteroskedastisitas yang diuraikan sebagai berikut:

i. Uji Normalitas, Dasar pengambilan keputusan bisa dilakukan berdasarkan probabilitas yaitu: Jika probabilitas > 0,05 maka distribusi dari populasi tersebut adalah normal. Jika probabilitas < 0,05 maka distribusi dari populasi tersebut adalah tidak normal. 
ii. Uji Multikolinieritas, Untuk mendeteksi ada tidaknya multikoliniearitas dalam model regresi dapat dilihat dari tolerancevalue atau Variance Inflation Factor (VIF). Nilai cutoff yang umum dipakai adalah: Jika nilai tolerance $>10$ persen dan nilai VIF < 10, maka dapat disimpulkan bahwa tidak ada multikolinearitas dalam model regresi. Jika nilai tolerance 10 persen dan niali VIF $>10$, maka dapat disimpulkan bahwa ada multikolinearitas model regresi.

iii. Uji Heteroskedastisitas, Dasar analisis ada atau tidaknya heteroskedastisitas dapat dilakukan sebagai berikut : Jika ada pola tertentu, seperti titik-titik yang ada membentuk pola tertentu yang teratur, maka diidentifikasikan telah terjadi heteroskedastisitas. Jika tidak ada pola jelas, serta titik-titik menyebar di atas dan di bawah angka 0 pada sumbu Y, maka tidak terjadi heteroskedastisitas.

Analisis regresi sederhana berguna untuk mencari hubungan fungsional satu variabel, atau untuk meramalkan satu variabel prediktor. Rumus persamaan regresi sederhana adalah sebagai berikut:

\begin{tabular}{|c|c|}
\hline & $Y=\mathbf{a}+\mathbf{b x}$ \\
\hline & $=$ Variab \\
\hline & $=$ Konsta \\
\hline & $=$ Koefisi \\
\hline & $=$ Variab \\
\hline
\end{tabular}

Sedangkan untuk rumus persamaan regresi bergandanya adalah sebagai berikut:

\begin{tabular}{|c|c|}
\hline & $\mathbf{Y}=\mathbf{a}+\mathbf{b}_{1} \mathbf{X}_{1}+\mathbf{b}_{2} \mathbf{X}_{2}+\mathbf{e}$ \\
\hline Y & $\begin{array}{l}=\text { Variabel dependen (kepuasan } \\
\text { pelanggan) }\end{array}$ \\
\hline $\mathrm{a}$ & $=$ Konstanta \\
\hline$b_{1} b_{2}$ & $=$ Koefisien garis regresi \\
\hline $\mathrm{X}_{1} \mathrm{X}_{2}$ & $\begin{array}{l}=\text { Variabel independen (etika bisnis } \\
\text { dan kualitas pelayanan) }\end{array}$ \\
\hline $\mathrm{e}$ & $=$ Error/variabel pengganggu \\
\hline
\end{tabular}

Koefisien determinasi $\left(\mathrm{R}^{2}\right)$ pada intinya mengukur seberapa jauh kemampuan model dalam menerangkan variasi variabel terikat. Rumusan untuk menghitung koefisien determinasi adalah sebagai berikut:

$$
\begin{aligned}
& \mathrm{KD}=\mathrm{r}^{2} \times 100 \% \\
\mathrm{KD} & =\text { Koefisien Determinasi } \\
\mathrm{r}^{2} & =\text { Koefisien Korelasi }
\end{aligned}
$$

\section{Uji hipotesis}

a. Uji signifikan parsial (uji-t), digunakan untuk mengetahui kemaknaan nilai koefisien regresi $\left(b_{1}\right.$ $\mathrm{b}_{2}$ ), sehingga dapat diketahui apakah pengaruh Etika Bisnis dan Kualitas Pelayanan $\left(X_{1}, X_{2}\right)$ berpengaruh signifikan atau tidak terhadap Kepuasan Pelanggan (Y). HoI: Tidak terdapat pengaruh Etika Bisnis $\left(\mathrm{X}_{1}\right)$ secara parsial terhadap Kepuasan Pelanggan (Y). $\quad \mathrm{Ha}_{l}$ :Terdapat pengaruh Etika Bisnis $\left(\mathrm{X}_{1}\right)$ secara parsial terhadap Kepuasan Pelanggan (Y). Hoz: Tidak terdapat pengaruh Kualitas Pelayanan $\left(\mathrm{X}_{2}\right)$ secara parsial terhadap Kepuasan Pelanggan (Y). $\mathrm{Ha}_{2}$ : Terdapat pengaruh Kualitas Pelayanan $\left(\mathrm{X}_{2}\right)$ secara parsial 
terhadap Kepuasan Pelanggan (Y). $\mathrm{Ho}_{3}$ : Tidak terdapat pengaruh Etika Bisnis $\left(\mathrm{X}_{1}\right)$ dan Kualitas Pelayanan $\left(X_{2}\right)$ secara simultan terhadap Kepuasan Pelanggan (Y). $\mathrm{Ha}_{3}$ : Terdapat pengaruh Etika Bisnis $\left(\mathrm{X}_{1}\right)$ dan Kualitas Pelayanan $\left(\mathrm{X}_{2}\right)$ secara simultan terhadap Kepuasan Pelanggan (Y).

b. Uji signifikas simultan (uji-f), digunakan untuk mengetahui tingkat

\section{HASIL DAN PEMBAHASAN}

\section{Analisis Statistik Deskriptif}

\section{a. Etika Bisnis $\left(\mathbf{X}_{1}\right)$}

Hasil tanggapan responden terhadap variabel etika bisnis dapat digambarkan sebagai berikut :

\section{Tabel 1}

Hasil Statistik Deskriptif Variabel $\mathbf{X}_{1}$

\begin{tabular}{|c|c|c|c|c|c|}
\hline & $\mathrm{N}$ & Min. & Max. & Mean & $\begin{array}{c}\text { Std. } \\
\text { Deviation }\end{array}$ \\
\hline $\begin{array}{l}\text { X1 } \\
\text { Valid N } \\
\text { (listwise) }\end{array}$ & $\begin{array}{l}92 \\
92\end{array}$ & $\begin{array}{r}65,0 \\
0\end{array}$ & $\begin{array}{r}110 \\
00\end{array}$ & $\begin{array}{r}88,369 \\
6\end{array}$ & 8,84384 \\
\hline
\end{tabular}

Sumber: Hasil Olah Data Penelitian dengan SPSS

Variabel Etika Bisnis mempunyai Nilai minimum sebesar 65,00 dan nilai maksimum sebesar 110,00 . Nilai mean 88,3696 dan standar deviasi sebesar8,84384, yang berarti nilai mean lebih besar dibandingkan dengan standardeviasi, sehingga mengidentifikasikan hasil sebaran data yang cukup baik.

\section{b. Kualitas Pelayanan $\left(\mathbf{X}_{2}\right)$}

Hasil tanggapan responden terhadap variabel kualitas pelayanan dapat digambarkan sebagai berikut :

Tabel 2

Hasil Statistik Deskriptif Variabel $\mathbf{X}_{2}$ signifikasi pengaruh variabel-variabel independen secara bersama-sama (simultan) terhadap variabel dependen. Dasar kepuasan pelanggan adalah dengan menggunakan angka probabilitas signifikansi, yaitu: Apabila probabilitas signifikansi > 0,05, maka $\mathrm{Ho}$ diterima dan $\mathrm{Ha}$ ditolak. Apabila probabilitas signifikansi < 0,05, maka Ho ditolak dan $\mathrm{Ha}$ diterima.

\begin{tabular}{|c|c|c|c|c|c|}
\hline & $\bar{N}$ & Min. & Max. & $\begin{array}{l}\text { Mean } \\
\end{array}$ & $\begin{array}{c}\text { Std. } \\
\text { Deviation }\end{array}$ \\
\hline x2 & 92 & $\begin{array}{r}99,0 \\
0\end{array}$ & $\begin{array}{r}160, \\
00\end{array}$ & \begin{tabular}{r|}
127,80 \\
43
\end{tabular} & 12,40900 \\
\hline $\begin{array}{l}\text { Valid N } \\
\text { (listwise) }\end{array}$ & 92 & & & & \\
\hline
\end{tabular}

Sumber: Hasil Olah Data Penelitian dengan SPSS

Variabel Kualitas Pelayanan mempunyai nilai minimum sebesar 99,00 dan nilai maksimum sebesar 160,00 . Nilai mean 127,8043 dan standar deviasi sebesar 12,40900 , yang berarti nilai mean lebih besar dibandingkan dengan standar deviasi, sehingga mengidentifikasikan hasil sebaran data yang cukup baik.

\section{c. Kepuasan Pelanggan (Y)}

Hasil tanggapan responden terhadap variabel kepuasan pelanggan dapat digambarkan sebagai berikut :

Tabel 3

Hasil Statistik Deskriptif Variabel $\mathbf{X}_{2}$

\begin{tabular}{|l|r|r|r|r|r|}
\hline & N & Min. & Max. & Mean & $\begin{array}{c}\text { Std. } \\
\text { Deviation }\end{array}$ \\
\hline Y & 92 & 37,00 & 60,00 & $\begin{array}{r}49,15 \\
22\end{array}$ & 5,83271 \\
$\begin{array}{l}\text { Valid N } \\
\text { (listwise) }\end{array}$ & 92 & & & & \\
\hline
\end{tabular}

Sumber: Hasil Olah Data Penelitian dengan SPSS

Variabel Kepuasan Pelanggan

mempunyai nilai minimum sebesar 37,00 dan nilai maksimum sebesar 
60,00 . Nilai mean 49,1522 dan standar deviasi sebesar 5,83271, yang berarti nilai mean lebih besar dibandingkan dengan standar

\section{Uji Instrumen Penelitian}

\section{a. Uji Validitas}

Pada penelitian ini, data berjumlah $\mathrm{n}$ $=30$, besarnya df dapat dihitung 30$2=28$, dengan alpha $=0,05$ didapat $\mathrm{r}_{\text {tabel }}$ dengan uji dua sisi $=0,361$. Dari hasil Uji Validitas menunjukkan bahwa nilai $r_{\text {hitung }}$ dari masingmasing variabel dinyatakan valid karena lebih besar dari $r_{\text {tabel }}$ yaitu memiliki nilai korelasi diatas0,361.

\section{b. Uji Reliabilitas}

Berikut iniadalah hasil uji reliabiltas ketiga variabel yaitu Etika Bisnis $\left(\mathrm{X}_{1}\right)$, Kualitas Pelayanan $\left(\mathrm{X}_{2}\right)$ dan Kepuasan Pelanggan (Y).

Tabel 4

Hasil Uji Reliabilitas Etika Bisnis (X1)

\begin{tabular}{|r|r|}
\hline Cronbach's Alpha & N of Items \\
\hline 933 & 22 \\
\hline
\end{tabular}

Sumber: Hasil Olah Data Penelitian dengan SPSS

Hasil uji menunjukan bahwa nilai cronbach's alpha sebesar 0,933 melebihi angka 0,60. Maka dapat dinyatakan bahwa variabel Etika $\operatorname{Bisnis}\left(\mathrm{X}_{1}\right)$ reliabel.

Tabel 5

Hasil Uji Reliabilitas Kualitas Pelayanan $\left(\mathbf{X}_{2}\right)$

\begin{tabular}{|r|r|}
\hline Cronbach's Alpha & N of Items \\
\hline, 874 & 12 \\
\hline
\end{tabular}

Sumber: Hasil Olah Data Penelitian dengan SPSS

Hasil uji menunjukan bahwa nilai cronbach's alpha sebesar 0,874 deviasi, sehingga

mengidentifikasikan hasil sebaran data yang cukup baik.

melebihi angka 0,60. Maka dapat dinyatakan bahwa variabel Kualitas Pelayanan $\left(\mathrm{X}_{2}\right)$ reliabel.

\section{Tabel 6}

Hasil Uji Reliabilitas Kepuasan

Pelaggan (Y)

\begin{tabular}{|c|c|}
\hline Cronbach's Alpha & $\mathrm{N}$ of Items \\
\hline ,912 & 12 \\
\hline
\end{tabular}

Hasil uji menunjukan bahwa nilai cronbach's alpha sebesar 0,912 melebihi angka 0,60. Maka dapat dinyatakan bahwa variabel Kepuasan Pelanggan(Y) reliabel.

\section{Uji Asumsi Klasik}

\section{a. Uji Normalitas}

Gambar histogram telah berbentuk lonceng yang menjukan bahwa data terdistribusi secara normal. Pada grafik $P$-P Plot terlihat titik-titik menyebar disekitar garis diagonal dan dekat dari garis diagonal menunjukan bahwa model regresi mengikuti asumsi normalitas.

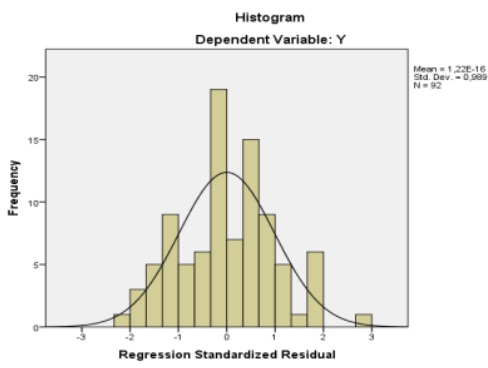




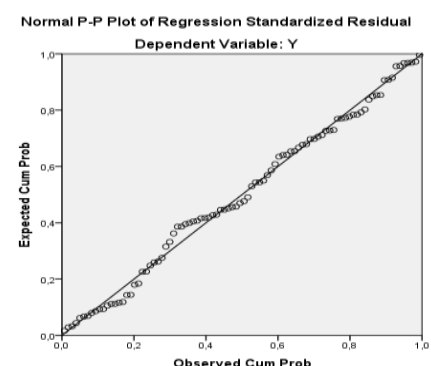

Gambar 2

Histogram dan P-plot diagram

Sumber: Hasil Olah Data Penelitian dengan SPSS

b. Uji Multikolinieritas

Berdasarkan hasil uji multikolinieritas didapat nilai VIF untuk variabel $\mathrm{X}_{1}$ dan $\mathrm{X}_{2}$ sebesar $1,836 \quad(<10)$ dan nilai tolerance sebesar 0,545 $(>0,1)$, maka dapat disimpulkan bahwa dalam penelitian ini tidak terjadi multikolinearitas.

\section{c. Uji Heteroskedastisitas}

Berdasarkan grafik Scatterplot ,terlihat titik-titik menyebar secara

\section{Uji Regresi Linear}

Dari hasil uji diperoleh persamaan regresi linear sederhana sebagai berikut:

$$
\mathbf{Y}=\mathbf{1 5 , 5 0 7 + 0 , 3 8 1} \mathrm{X}_{1}
$$

Nilai $\mathrm{a}=15,507$ dimana besarnya kepuasan Pelanggan 15,507. Apabila Etika Bisnis adalah nol. Nilai $b=0,381$ artinya ada pengaruh yang positif antara etika bisnis terhadap kepuasan pelanggan.

Tabel 7

Hasil Uji Regresi Linear Sederhana Variabel $X_{1}$ terhadap $Y$

Coefficients $^{\mathrm{a}}$

\begin{tabular}{|l|c|c|c|c|}
\hline Model & $\begin{array}{c}\text { Unstandardized } \\
\text { Coefficients }\end{array}$ & $\begin{array}{c}\text { Standar } \\
\text { dized } \\
\text { Coeffici } \\
\text { ents }\end{array}$ & $t$ & Sig. \\
\hline
\end{tabular}

acak tidak membentuk sebuah pola tertentu yang jelas secara tersebar baik diatas maupun dibawah angka nol pada sumbu y. Hal ini berarti tidak terjadi Heteroskedastisitas pada model regresi sehingga model regresi layak dipakai untuk melihat pengaruh variabel independen terhadap variabel dependen.

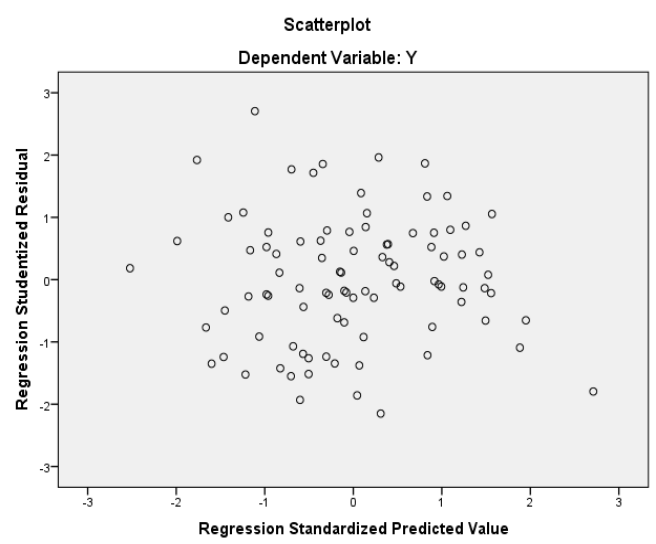

Gambar 3

Hasil Uji Heteroskedastisitas

Sumber: Hasil Olah Data Penelitian dengan SPSS

\begin{tabular}{|r|r|r|r|r|r|}
\hline & B & $\begin{array}{c}\text { Std. } \\
\text { Error }\end{array}$ & Beta & & \\
\hline $\begin{array}{l}\text { (Const } \\
\text { ant) } \\
\text { X1 }\end{array}$ & 15,507 & 5,041 & & 3,076 &, 003 \\
&, 381 &, 057 &, 577 & 6,707 &, 000 \\
\hline
\end{tabular}

a. Dependent Variable: $Y$

Sumber: Hasil Olah Data Penelitian dengan SPSS

Dari hasil uji diperoleh persamaan regresi linear sederhana sebagai berikut:

$$
\mathrm{Y}=\mathbf{5 , 4 2 1}+\mathbf{0 , 3 4 2} \mathrm{X}_{\mathbf{2}}
$$

Nilai $\mathrm{a}=5,421$ dimana besarnya kepuasan pelanggan5,421apabila kualitas pelayanan adalah nol. Nilai $b=$ 0,342 artinya ada pengaruh yang positif antara etika bisnis terhadap kepuasan pelanggan. 
Tabel 8

Hasil Uji Regresi Linier Sederhana

Variabel $\mathrm{X}_{2}$ terhadap $\mathrm{Y}$

Coefficients $^{\mathrm{a}}$

\begin{tabular}{|c|r|r|r|r|r|}
\hline Model & \multicolumn{2}{|c|}{$\begin{array}{c}\text { Unstandardized } \\
\text { Coefficients }\end{array}$} & $\begin{array}{r}\text { Standar } \\
\text { dized } \\
\text { Coeffici } \\
\text { ents }\end{array}$ & $\mathrm{t}$ & \multirow{2}{*}{ Sig. } \\
\cline { 2 - 4 } & $\mathrm{B}$ & $\begin{array}{r}\text { Std. } \\
\text { Error }\end{array}$ & \multicolumn{1}{|c|}{ Beta } & & \\
\hline $\begin{array}{r}\text { (Const } \\
\text { ant) } \\
\text { X2 }\end{array}$ & 5,421 & 4,362 & & 1,243 &, 217 \\
&, 342 &, 034 &, 728 & 10,073 &, 000 \\
\hline
\end{tabular}

a. Dependent Variable: $Y$

Sumber: Hasil Olah Data Penelitian dengan SPSS

Dari hasil uji diperoleh persamaan regresi linear berganda sebagai berikut:

$$
\mathbf{Y}=\mathbf{2 , 6 1 9}+\mathbf{0 , 1 0 4} \mathrm{X}_{1}+\mathbf{0 , 2 9 2} \mathrm{X}_{2}+\mathrm{e}
$$

2,619 adalah konstanta, jika diasumsikan etika bisnis $\left(\mathrm{X}_{1}\right)$ dan kualitas pelayanan $\left(\mathrm{X}_{2}\right)$ konstan atau sama dengan 0, maka nilai kepuasan pelanggan (Y) sebesar 2,619. Selanjutnya 0,104 diartikan jika etika bisnis $\left(\mathrm{X}_{1}\right)$ naik 1 satuan maka nilai kepuasan pelanggan (Y) akan meningkat sebesar 0,104 dengan asumsi variabel lain konstan. Berikutnya 0,292 diartikan jika kualitas pelayanan $\left(\mathrm{X}_{2}\right)$ naik 1 satuan maka nilai kepuasan pelanggan (Y) akan meningkat sebesar 0,292 dengan asumsi variabel lain konstan.

Tabel 9

Hasil Uji Regresi Berganda $\left(X_{1}\right)$ dan $\left(X_{2}\right)$

Terhadap (Y)

Coefficients $^{\mathrm{a}}$

\begin{tabular}{|l|r|r|r|r|r|}
\hline Model & \multicolumn{2}{|c|}{$\begin{array}{c}\text { Unstandardized } \\
\text { Coefficients }\end{array}$} & $\begin{array}{r}\text { Standar } \\
\text { dized } \\
\text { Coeffici } \\
\text { ents }\end{array}$ & t & Sig. \\
\cline { 2 - 4 } & \multicolumn{1}{|c|}{ B } & $\begin{array}{r}\text { Std. } \\
\text { Error }\end{array}$ & Beta & & \\
\hline $\begin{array}{l}\text { (Con } \\
\text { stant }\end{array}$ & 2,619 & 4,653 & &, 563 &, 575 \\
) &, 104 &, 064 &, 158 & 1,627 &, 107 \\
\hline
\end{tabular}

\begin{tabular}{|l|l|l|l|l|l|}
\hline $\mathrm{X} 2$ &, 292 &, 046 &, 621 & 6,403 &, 000 \\
\hline
\end{tabular}

a. Dependent Variable: $Y$

Sumber: Hasil Olah Data Penelitian dengan SPSS

\section{Uji Koefisien Determinasi $\left(\mathbf{R}^{\mathbf{2}}\right)$}

Berdasarkan hasil uji diketahui besarnya RSquare adalah 0,333 artinya variabel etika bisnis memengaruhi kepuasan pelanggan sebesar $33,3 \%$.

Tabel 10

\section{Hasil Uji Koefisien Determinasi Variabel $X_{1}$ terhadap $Y$}

\begin{tabular}{|r|c|c|c|c|}
\hline Model & $\mathrm{R}$ & $\begin{array}{c}\mathrm{R} \\
\text { Square }\end{array}$ & $\begin{array}{c}\text { Adjusted } \\
\mathrm{R} \\
\text { Square }\end{array}$ & $\begin{array}{c}\text { Std. } \\
\text { Error of } \\
\text { the } \\
\text { Estimate }\end{array}$ \\
\hline 1 &, $577^{\mathrm{a}}$ &, 333 &, 326 & 4,78906 \\
\hline
\end{tabular}

a. Predictors: (Constant), X1

Sumber: Hasil Olah Data Penelitian dengan SPSS

Berdasarkan hasil uji diketahui besarnya $R$ Square adalah 0,530 artinya variabel kualitas pelayanan memengaruhi kepuasan pelanggan sebesar $53 \%$.

\section{Tabel 11}

\section{Hasil Uji Koefisien Determinasi} Variabel $\mathbf{X}_{2}$ terhadap $\mathbf{Y}$

\begin{tabular}{|l|r|r|r|r|}
\hline Model & $\mathrm{R}$ & $\begin{array}{c}\mathrm{R} \\
\text { Square }\end{array}$ & $\begin{array}{c}\text { Adjusted } \\
\mathrm{R} \\
\text { Square }\end{array}$ & $\begin{array}{c}\text { Std. } \\
\text { Error of } \\
\text { the } \\
\text { Estimate }\end{array}$ \\
\hline 1 &, $728^{\mathrm{a}}$ &, 530 &, 525 & 4,02109 \\
\hline
\end{tabular}
a. Predictors: (Constant), X2
Sumber: Hasil Olah Data Penelitian dengan
SPSS

Berdasarkan hasil uji diketahui koefisien determinasi $R$ Square adalah sebesar 0,544. Dengan demikian besarnya pengaruh yang diberikan oleh variabel 
etika bisnis $\left(\mathrm{X}_{1}\right)$ dan variabel kualitas pelayanan $\left(\mathrm{X}_{2}\right)$ terhadap kepuasan pelanggan adalah 54,4\%

Tabel 12

Hasil Uji Koefisien Determinasi

Variabel $X_{1}$ dan $X_{2}$ Terhadap $Y$

\begin{tabular}{|l|c|r|r|r|}
\hline Model & $R$ & $\begin{array}{c}R \\
\text { Square }\end{array}$ & $\begin{array}{c}\text { Adjusted } \\
\mathrm{R} \\
\text { Square }\end{array}$ & $\begin{array}{c}\text { Std. } \\
\text { Error of } \\
\text { the } \\
\text { Estimate }\end{array}$ \\
\hline 1 &, $737^{\mathrm{a}}$ &, 544 &, 533 & 3,98477 \\
\hline
\end{tabular}

Sumber: Hasil Olah Data Penelitian dengan SPSS

\section{Uji Hipotesis}

\section{a. Uji Sigifikansi Parsial (Uji t)}

Dari hasil uji diperoleh thitung sebesar 6,707artinya $t_{\text {hitung }}>t_{\text {tabel }}(6,707>$ 1,986) dengan signifikansi $0,000<$ 0,05. Maka dapat disimpulkan Ho ditolak dan $\mathrm{Ha}$ diterima. Artinya terdapat pengaruh yang signifikan etika bisnis terhadap kepuasan pelanggan.

\section{Tabel 13}

\section{Hasil Uji t Variabel $X_{1}$ Terhadap $Y$ Coefficients $^{\mathrm{a}}$}

\begin{tabular}{|c|r|r|r|r|r|}
\hline Model & \multicolumn{2}{|c|}{$\begin{array}{c}\text { Unstandardized } \\
\text { Coefficients }\end{array}$} & $\begin{array}{c}\text { Standar } \\
\text { dized } \\
\text { Coeffici } \\
\text { ents }\end{array}$ & t & \multirow{2}{*}{ Sig. } \\
\cline { 2 - 5 } & \multicolumn{1}{|c|}{$\mathrm{B}$} & $\begin{array}{r}\text { Std. } \\
\text { Error }\end{array}$ & Beta & & \\
\hline $\begin{array}{l}\text { (Const } \\
\text { ant) } \\
\text { X1 }\end{array}$ & 15,507 & 5,041 & & 3,076 &, 003 \\
\hline
\end{tabular}

a. Dependent Variable: $Y$

Sumber: Hasil Olah Data Penelitian dengan SPSS

Dari hasil uji diperoleh thitung sebesar 10,073 artinya $t_{\text {hitung }}>t_{\text {tabel }}(10,073>$ 1,986) dengan signifikansi $0,000<$ 0,05. Maka dapat disimpulkan Ho ditolak dan $\mathrm{Ha}$ diterima. Artinya terdapat pengaruh yang signifikan kualitas pelayanan terhadap kepuasan pelanggan.
Tabel 14

Hasil Uji t Variabel $X_{2}$ Terhadap Y

Coefficients $^{a}$

\begin{tabular}{|c|c|c|c|c|c|}
\hline \multirow[t]{2}{*}{ Model } & \multicolumn{2}{|c|}{$\begin{array}{l}\text { Unstandardize } \\
\text { d Coefficients }\end{array}$} & $\begin{array}{l}\text { Standardized } \\
\text { Coefficients }\end{array}$ & \multirow[t]{2}{*}{$\mathrm{T}$} & \multirow[t]{2}{*}{ Sig. } \\
\hline & B & $\begin{array}{l}\text { Std. } \\
\text { Error }\end{array}$ & Beta & & \\
\hline $\begin{array}{l}\text { (Const } \\
\text { ant) }\end{array}$ & 5,421 & 4,362 & & 1,243 & ,217 \\
\hline $\mathrm{X} 2$ & ,342 & ,034 & ,728 & 10,073 &, 000 \\
\hline
\end{tabular}

a. Dependent Variable: $Y$

Sumber Hasil Olah Data Penelitian dengan SPSS

\section{b. Uji Signifikansi Simultan (Uji F)}

Nilai $\mathrm{F}_{\text {tabel }}$ diperoleh dari $\mathrm{df}_{1}=92-2$ $1=89, \mathrm{df}_{2}=2$ dengan tingkat kesalahan 5\% sehingga didapat hasil 3,10. Berdasarkan tabel di atas, $F_{\text {hitung }}(52,987)>F_{\text {tabel }}(3,10)$ dan sig $(0,000)<0,05$ maka etika bisnis dan kualitas pelayananberpengaruh signifikan secara bersama-sama (simultan) terhadap kepuasan pelanggan.

Tabel 15

Hasil Uji F Variabel

$\mathbf{X}_{1}$ dan $\mathbf{X}_{2}$ Terhadap $\mathbf{Y}$ ANOVAa

\begin{tabular}{|c|c|c|c|c|c|}
\hline Model & $\begin{array}{l}\text { Sum of } \\
\text { Squares }\end{array}$ & $\mathrm{df}$ & $\begin{array}{l}\text { Mean } \\
\text { Square }\end{array}$ & $F$ & Sig. \\
\hline $\begin{array}{l}\text { Regre } \\
\text { ssion }\end{array}$ & $\begin{array}{r}1682,69 \\
0\end{array}$ & 2 & 841,345 & $\begin{array}{r}52,9 \\
87\end{array}$ & $\begin{array}{r}, 00 \\
0^{b}\end{array}$ \\
\hline $\begin{array}{ll}\text { Resid } \\
\text { ual }\end{array}$ & $\begin{array}{r}1413,17 \\
9\end{array}$ & 89 & 15,878 & & \\
\hline Total & $\begin{array}{r}3095,87 \\
0\end{array}$ & 91 & & & \\
\hline
\end{tabular}

a. Dependent Variable: $Y$ 
b. Predictors: (Constant), X2, X1

Sumber: Hasil Olah Data Penelitian

\section{E. KESIMPULAN DAN SARAN}

\section{Kesimpulan}

Berdasarkan hasil penelitian ini, maka diperoleh kesimpulan sebagai berikut :

a. Dari nilai konstanta pada hasil uji regresi linear berganda, menunjukkan bahwa etika bisnis $\left(\mathrm{X}_{1}\right)$ dan kualitas pelayanan $\left(\mathrm{X}_{2}\right)$ akan mempengaruhi nilai kepuasan pelanggan (Y) sebesar 2,619. Jika etika bisnis $\left(\mathrm{X}_{1}\right)$ naik 1 satuan maka nilai kepuasan pelanggan (Y) akan meningkat sebesar 0,104. Berikutnya jika kualitas pelayanan $\left(\mathrm{X}_{2}\right)$ naik 1 satuan maka nilai kepuasan pelanggan (Y) akan meningkat sebesar 0,292 dengan asumsi variabel lain konstan.

b. Dari hasil uji parsial dari tiap-tiap variable, dibuktikan bbahwa nilai $\mathrm{t}_{\text {hitung }}>\mathrm{t}_{\text {tabel }}$ dan nilai probabilitas sigifikansi 0,000 lebih kecil dari 0,05 maka Hol dan Hor ditolak dan $\mathrm{Ha} 1$ dan Ha2 diterima. Artinya tiap-tiap variabel, Etika Bisnis (X1) dan Kualitas Pelayanan (X2) secara parsial mempunyai pengaruh yang signifikan terhadap Kepuasan Pelanggan di PT. Modern Multi Kemasindo. dengan SPSS

c. Dari hasil uji signifikansi simultan (Uji F) diketahui nilai $F_{\text {hitung }}$ 52,987 > $F_{\text {tabel }} 3,10$ dengan probabilitas signifikan sebesar 0,000 lebih kecil dari 0,05. Artinya hal ini membuktikan bahwa terdapat pengaruh Etika Bisnis $\left(\mathrm{X}_{1}\right)$ dan Kulitas Pelayanan $\left(\mathrm{X}_{2}\right)$ terhadap Kepuasan Pelanggan (Y) secara bersamasama di PT. Modern Multi Kemasindo.

\section{Keterbatasan}

Penelitian ini memiliki beberapa keterbatasan yang dialami selama proses penelitian berlangsung yaitu sebagai berikut:

a. Masih terbatasnya variable yang belum diangkat pada penelitian ini dan masih minimnya atribut yang belum dikembangkan.

b. Jawaban responden yang disampaikan secara tertulis pada kuesioner belum tentu mencerminkan keadaan yang sesungguhnya.

c. Masih terbatasnya Jumlah responden dan jangkauan wilayah penelitiaan.

\section{Saran}

Agar lebih mengembangkan niai penelitian ini di masa mendatang, maka berdasarkan keterbatasan penelitian di atas, peneliti memberikan beberapa rekomendasi sebagai berikut:

a. Mengembangkan jangkauan wilayah penelitian dengan variasi jenis industri yang lebih bervariasi agar didapatkan hasil penelitian yang lebih baik. 
b. Untuk penelitian di masa mendatang agar lebih mengembangkan variabel sehingga didapatkan hasil riset yang lebih komprehensif.

c. Untuk penelitian di masa mendatang sebaiknya di

\section{F. DAFAR PUSTAKA}

Abdullah, Thamrin \& Francis Tantri. 2018. Manajemen Pemasaran. Depok: PT Rajagrafindo Persada.

Abdurrahman \& Sanusi. 2015. Manajemen Strategi. Bandung: CV PustakaSetia.

Amal, Masyrifatul. 2017. Pengaruh Kulaitas Pelayanan Terhadap Kepuasan Pelanggan (studi kasus pada Dealer Resmi Honda Kompo Purbalingga). Purbalingga.

Ardiansyah, Tri Endi. 2018, Etika Komuikasi Bisnis, Tangerang: Modul Kuliah, Fakultas Ekonomi Dan Bissnis, Universitas Muhammadiyah Tangerang.

Armstrong, Kotler 2015, "Marketing is an Introducing Prentice Hall twelft edition", England : Pearson Education, Inc

Assauri, Sofjan. 2013. Manajemen Pemasaran. Jakarta: Raja Grafindo.

Bayhaki.2016. Analisis Kualitas Pelayanan Dan Personal Selling Terhadap Kepuasan Pelanggan Pada PT Subur Makmur Sentosa Cikupa.Tangerang: Fakultas Ekonomi dan Bisnis Universitas Muhammadiyah Tangerang. rancangan Materi survey/kuisioner yang lebih fleksibel dan attractive sehingga mendorong responden untuk lebih terbuka dan jujur dalam menjawab survey/kuisioner.

Creswell, Jhon W. 2016. Research Design Pendekatan Kualitatif, Kuantitatif, dan Mixed. Yogyakarta: Pustaka Pelajar.

Efendi, Sari. 2018. Pengaruh Harga dan Kualitas Pelayanan Terhadap Kepuasan Pelanggan PT Telkom Indonesia (Studi Kasus Pada Pelanggan Plasa Telkom Iskandar Muda Medan).

Fahmi, Irham. 2017. Etika Bisnis: Teori Kasus, dan Solusi. Bandung: Alfabeta

Fauzan, dan Nuryana, Ida. 2014. Pengaruh Penerapan Etika Bisnis Terhadap Kepuasan Pelanggan Warung Bebek $H$. Slamet di Kota Malang. Malang.

Ghozali, Imam. 2018. Aplikasi Analisis Multivariate dengan Program IBM SPSS 25. Badan Penerbit Universitas Diponegoro: Semarang

http://www.kemenperin.go.id/diakses pada 20 April 201916.10

https://www.academia.edu/37506558/Eti ka_Bisnis diakses pada 5 Agustus 201921.44

Kotler, Philip dan Kevin Lane keller. $2018 . \quad$ Manajemen PemasaranEdisi Ke-13 Jilid Jakarta: Erlangga.

Lubis, Alfi Syahri dan Andayani, Nur Rahmah.2017. Pengaruh Kualitas Pelayanan (Service Quality) Terhadap Kepuasan 
Pelanggan PT. Sucofindo Batam.Batam.

Musyana, Suyadi, Bambang, dan Suharso, Pudjo. 2017. Kepuasan Konsumen di Pasar Mimbaan Kecamatan Panji Kabupaten Situbondo.Situbondo.

Novriandi.2018. Pengaruh Kualitas

Pelayanan Dan Kualitas

Produk Terhadap Kepuasan

Pelanggan Pada PT Indonesia

Media

Televisi

(BIGTV).Tangerang: Fakultas

Ekonomi Dan Bisnis

Universitas Muhammadiyah

Tangerang.

Nurhayati $\mathrm{H}$, Suharto $\mathrm{T}$, dan Wahyuningsih N. 2017.Pengaruh Penerapan Etika Bisnis Islam dan Kualitas Pelayanan Terhadap Kepuasan Anggota pada BMT Al-Islihah Cabang
Prihanto, Hendi, 2018, Etika Bisnis \& Profesi Sebuah Pencarian, Edisi ke-1 Cetakan ke-1, Depok: Rajawali Pers.

Sudaryono. 2016. Manajemen Pemasaran, Teori \& Implementasi. Yogyakarta: Andi.

Sugiyono. 2014. Metode Penelitian Kuantitatif, Kualitatif, dan Kombinasi (Mixed Methods). Bandung: Alfabeta

Tjiptono, Fandy \& Gregorius Chandra. 2017. Pemasaran Strategik Edisi 3. Yogyakarta: Andi.

Wardhana, Aditya dan Sembiring, Esra. 2015. Pengaruh Kualitas Pelayanan Teller Terhadap Kepuasan Nasabah pada PT. Bank Rakyat Indonesia (Persero) Tbk Kantor Unit Kemang Cabang Bogor. Bogor.

Rajagaluh.Majalengka. 